\title{
http://www.revistas.ufg.br/index.php/atelie
}

\section{Os projetos pedagógicos dos cursos de formação de professores de Geografia após a aprovação das Diretrizes Curriculares Nacionais}

\author{
The pedagogical projects of the Geography teachers \\ training courses after the approval of the National \\ Curricular Guidelines
}

\section{Los proyectos pedagógicos de los cursos de formación de los profesores de Geografía después de la aprobación de las Directrices Curriculares Nacionales}

\author{
Eliana Marta Barbosa de Morais \\ Instituto de Estudos Socioambientais-UFG \\ elianamarta.ufg@gmail.com \\ Adriana Olivia Alves \\ Instituto de Estudos Socioambientais-UFG \\ adrianaolivia.ufg@gmail.com \\ Miriam Aparecida Bueno \\ Instituto de Estudos Socioambientais-UFG \\ miriam.cerrado@gmail.com
}

\begin{abstract}
Resumo
Objetiva-se analisar a formação de professores de Geografia em diferentes Instituições de Ensino Superior (IES) no Brasil, avaliando as alterações ocorridas na formação inicial no período de 2002 a 2012 em função das Diretrizes Curriculares Nacionais (DCN's). Trata-se de uma pesquisa coletiva desenvolvida no âmbito do Núcleo de Ensino e Pesquisa em Educação Geográfica (NEPEG), que agrega pesquisadores de diferentes IES brasileiras. A problemática da formação de professores de Geografia no âmbito das DCN's envolve o contexto político da educação brasileira; o cenário de sua implantação; e os impactos já percebidos na formação de professores de Geografia em função dessas DCN's. Apresentar-se-á nesse artigo a primeira etapa da pesquisa, qual seja, a análise dos projetos pedagógicos das instituições envolvidas, para conhecer a relação do projeto com as DCNs; a concepção do estágio e da prática como componente curricular; a relação teoria e prática; a posição e a carga horária das disciplinas pedagógicas, destacando
\end{abstract}


as convergências e divergências quanto ao embate entre legislação e projeto pedagógico.

Palavras-chave: Diretrizes Curriculares Nacionais; Projetos Pedagógicos; Formação de Professores em Geografia; Brasil

\begin{abstract}
The objective of this study is to analyze the training of Geography teachers in different Institutions of Higher Education (IES) in Brazil, evaluating the changes that occurred in the initial formation in the period from 2002 to 2012 according to the National Curricular Guidelines (DCNs). This is a collective research carried out within the scope of the Teaching and Research Core in Geographic Education (NEPEG), which brings together researchers from different Brazilian IESs. The problematic of the formation of Geography teachers in the scope of the DCNs involves the political context of the Brazilian education; the scenario of its implementation; and the impacts already perceived in the training of Geography teachers in function of these DCN's. This article will present the first stage of the research, that is, the analysis of the pedagogical projects of the institutions involved, to understand the relation of the project with the DCNs; the conception of the stage and practice as a curricular component; the relation between theory and practice; the position and the time load of the pedagogical disciplines, highlighting the convergences and divergences regarding the clash between legislation and pedagogical project.
\end{abstract}

Keywords: National Curricular Guidelines; Pedagogical Projects; Teacher Training in Geography; Brazil

\title{
Resumen
}

Se pretende analizar la formación de profesores de Geografía en diferentes IES Instituciones de Enseñanza Superior en Brasil, analizando las alteraciones ocurridas en la formación inicial en el período de 2002 a 2012, en función de las DCN Directrices Curriculares Nacionales. Se trata de una investigación colectiva desarrollada en el ámbito del Núcleo de Enseñanza e Investigación en Educación Geográfica, NEPEG, que añade investigadores de diferentes IES brasileñas. La problemática de la formación de profesores de Geografía en el ámbito de las DCN está involucrada en el contexto político de la educación brasileña; el formato de su implantación; y los impactos ya observados en la formación de profesores de Geografía en función de esas DCN. Se presentará en este artículo la primera etapa de la investigación, que será el análisis de los proyectos pedagógicos de las instituciones involucradas, para conocer la relación del proyecto con las DCN; la concepción de las prácticas profesionales y de la práctica como componente curricular; la relación teoría y práctica; la posición y la carga horaria de las disciplinas pedagógicas, destacando las afinidades y diferencias sobre los ataques entre la legislación y el proyecto pedagógico.

Palabras-clave: Directrices Curriculares Nacionales. Proyectos pedagógicos. Formación de Profesores de Geografía. Brasil.

\section{Considerações iniciais}

As discussões acerca das Diretrizes Curriculares Nacionais (DCNs) brasileiras, aprovadas em 2002, tiveram seu debate fortalecido a partir dos anos 2000, quando o 
Ministério da Educação encaminhou para o Conselho Nacional de Educação (CNE), para apreciação, a proposta de Diretrizes para a Formação de Professores da Educação Básica, em cursos de nível superior, conforme apresentado no parecer do $\mathrm{CNE}-\mathrm{CP}$ 9/2001, de 08 de maio de 2001. Foi esse parecer, através da Resolução CNE/CP 1, de 18 de fevereiro de 2002, que instituiu as DCNs para a Formação de Professores da Educação Básica, em nível superior, em cursos de licenciatura, de graduação plena.

A apresentação da proposta das DCNs ao Conselho Pleno do Conselho Nacional de Educação, última instância antes do encaminhamento da mesma à apreciação do ministro da Educação, ocorreu em 08 de maio de 2001 . O documento que hoje constitui as Diretrizes para a Formação de Professores da Educação Básica, em cursos de nível superior, havia sido (março de 2001) submetido à apreciação da comunidade educacional em audiências públicas regionais, em reunião institucional, em reunião técnica e em audiência pública nacional (Parecer do CNE-CP 9/2001, de 08 de maio de 2001).

Dentre as justificativas apresentadas nesse parecer para a instituição das DCNs, os relatores destacaram o preparo inadequado dos professores, que, segundo eles, se mantiveram, ao longo dos últimos anos, assentados num formato de ensino tradicional incondizente com o que se almeja para a atuação docente. Enquanto a comunidade científica defende que o ensino medeie e oriente a aprendizagem dos alunos; comprometa-se com o sucesso da aprendizagem destes; assuma e lide com a diversidade existente entre os alunos; incentive o desenvolvimento de atividades de enriquecimento cultural; promova práticas investigativas; execute projetos para desenvolver conteúdos curriculares; utilize novas metodologias, estratégias e materiais de apoio, e favoreça o desenvolvimento de hábitos de colaboração e trabalho em equipe, a formação docente continua assentada em parâmetros tradicionais, que dificultam o alcance desses objetivos (CNE-CP Nº9, de 08 de maio de 2001).

Embora sejam apresentadas as dificuldades para o alcance da aprendizagem, em virtude de uma formação docente que não condiz com o que se almeja desse profissional na atualidade, esse documento destaca que, além das mudanças que se fazem necessárias nos cursos de formação docente (O que justifica a elaboração e aprovação das DCNs), essa melhoria vai depender também de políticas que fortaleçam a profissionalidade docente; do estabelecimento de uma formação continuada que fortaleça o vínculo entre as instituições formadoras e as de Educação Básica; de melhorias na infraestrutura institucional que definam jornada de trabalho e planos de carreiras compatíveis com o exercício profissional do docente. Portanto, a reflexão sobre o fazer docente apresentada nesse parecer indica que não é possível analisar a construção de aprendizagens desvinculadas de reflexões que vão além da sala de aula e que, de igual maneira, afetam a atuação desses profissionais.

Foi com base nas justificativas apresentadas por esse parecer que foram aprovadas as DCNs, documento esse que ampara a investigação que será levada a cabo no presente trabalho. A Resolução CNE/CP 1, de 18 de fevereiro de 2002, que aprovou as Diretrizes Curriculares Nacionais para a Formação de Professores da Educação 
Básica, em nível superior, em curso de licenciatura, de graduação plena, explicita em seu primeiro artigo que as DCNs são constituídas por um conjunto de princípios, fundamentos e procedimentos a serem observados na organização institucional e curricular de cada estabelecimento de ensino e aplicam-se a todas as etapas e modalidades da educação básica.

Conjunto este que passou a nortear a organização curricular das diversas áreas do conhecimento situadas no ensino superior que possuem a sua correspondente na Educação Básica, como a formação do Licenciado em Geografia.

Nesse documento, são apresentados, também, três princípios básicos para a formação de professores, com vistas à sua atuação na Educação Básica. O primeiro princípio circunscreve-se à competência, apresentado como uma concepção nuclear na orientação do curso. Ser competente significa estar preparado para a sua futura atuação profissional. Como segundo princípio, evidencia-se a coerência entre a formação oferecida nos cursos de nível superior e a prática esperada do futuro professor. O último princípio diz respeito à pesquisa, com foco no processo de ensino e de aprendizagem. A defesa é a de que "ensinar requer tanto dispor de conhecimentos e mobilizá-los para a ação como compreender o processo de construção do conhecimento" (Resolução $\mathrm{CNE} / \mathrm{CP} 1$, de 18 de fevereiro de 2002).

Outras questões apresentadas nessa resolução referem-se à indicação de que os cursos de formação de professores em nível superior terão a sua duração definida pelo Conselho Pleno; a prática, na matriz curricular, não poderá ficar restrita ao estágio e deverá ser realizada desde o início do curso; o estágio curricular supervisionado deverá ser realizado em escola de Educação Básica a partir do regime de colaboração entre os sistemas de ensino, e deve ser desenvolvido desde o início da segunda metade do curso ${ }^{1}$.

Assim, foi a Resolução CNE/CP 2, de 19 de fevereiro de 2002, que instituiu a duração e a carga horária dos cursos de licenciatura, de graduação plena, de formação de professores da Educação Básica em nível superior. De acordo com essa resolução, a carga horária dos cursos deverá ser efetivada mediante a integralização de, no mínimo, 2.800 (duas mil e oitocentas) horas, articuladas a partir da relação teoria-prática e estruturadas segundo as seguintes dimensões dos componentes comuns:

I - 400 (quatrocentas) horas de prática como componente curricular, vivenciadas ao longo do curso;

II - 400 (quatrocentas) horas de estágio curricular supervisionado a partir do início da segunda metade do curso;

III - 1.800 (mil e oitocentas) horas de aulas para os conteúdos curriculares de natureza científico-cultural;

\footnotetext{
${ }^{1}$ Esses temas serão objeto de nossa análise no próximo item, momento em que serão discutidos os projetos pedagógicos das instituições envolvidas na pesquisa.
} 
IV - 200 (duzentas) horas para outras formas de atividades acadêmico-científico-culturais.

(RESOLUÇÃO CNE/CP 2, DE 19 DE FEVEREIRO DE 2002)

Essa carga horária deve ser realizada considerando a compatibilidade com o que está disposto na LDB, ou seja, 200 (duzentos) dias letivos ao ano, com duração mínima de 3 (três) anos letivos.

Conforme vimos destacando até aqui, são variados os temas presentes nas DCNs. O que evidencia, por sua vez, distintas e até mesmo divergentes concepções, quando o tema se coloca no centro do debate. É nesse sentido que, considerando-se o contexto histórico e suas finalidades, as DCNs vêm promovendo intensos debates no território nacional, num cenário marcado por divergências entre o Ministério da Educação, responsável pelo processo de implantação das diretrizes, e os educadores brasileiros, em especial aqueles que são militantes políticos e aqueles que atuam com a formação de professores no Brasil.

Esse processo de reforma tem trazido à tona divergências como o tempo mínimo de formação profissional. Denúncias em torno do aligeiramento da formação dos professores foram expressas pelos educadores em consideração à Resolução $\mathrm{CNE} / \mathrm{CP} \mathrm{n}^{\circ}$ $2 / 2002$, que estabeleceu a duração dos cursos de licenciatura. De acordo com Freitas (2002), em decorrência das pressões do setor privado, o tempo de formação do professor foi reduzido de 3.200 horas para 2.800 horas. Do ponto de vista do poder público, a redução do tempo de formação ocorreu em virtude do expressivo número de professores em exercício no magistério sem a devida habilitação para essa função.

Outro debate foi posto à proibição da formação do licenciado e do bacharel concomitantemente. Tal proibição resultou em forte reação de educadores, instituições de pesquisa e agremiações profissionais, as quais utilizavam o argumento de que ambos devem ter as mesmas bases teórico-metodológicas que conformam a ciência geográfica. Diversos eventos científicos realizados nesse período evidenciavam as bases em que se sustentava esse debate, em especial, destacando a supremacia da formação do bacharel em relação ao professor.

Evidenciam-se também, nessas propostas, pontos convergentes, a exemplo das concepções em torno da necessidade de ampliar a associação entre a pesquisa e o ensino, de articular teoria e prática e construir um currículo menos fragmentado, que integre as áreas essenciais para a formação do professor. Debate este já presente em diversos teóricos da educação, como Pimenta (1988).

Pode-se dizer que os impactos dessas políticas têm tido forte incidência na estruturação e na qualidade da formação empreendida nos cursos de formação de professores, somando-se àquelas já citadas os debates em torno do Estágio Supervisionado e das Práticas como Componente Curricular (MORAIS; OLIVEIRA, 2008). 
Constata-se que a temática, a despeito de estar materializada numa base legal, ainda carece de reflexões e precisa ser discutida pelos sujeitos que estão direta ou indiretamente envolvidos no processo de formação de professores. A necessidade de ajustes sobre o processo se revela pelos impactos gerados em decorrência da implementação da legislação. Sendo assim, de que forma as mudanças trazidas pelas DCN's contribuiriam para a formação do professor nos cursos de licenciatura? Além desses, que outros problemas permeiam o processo de formação docente? Que impactos são específicos aos cursos de Geografia das IES públicas? Quais as possibilidades de sucesso diante das demandas da contemporaneidade? Quais seriam os ajustes a serem efetuados para melhorar o processo de formação de professores?

Diante dessas e de outras questões, torna-se necessário conhecer as diversas experiências de formação desse profissional, no intuito de subsidiar os debates e propor encaminhamentos para a formação do professor de Geografia.

É considerando a análise e os desdobramentos em torno desses pareceres e resoluções que objetiva-se, na presente pesquisa, analisar a formação de professores de Geografia em diferentes Instituições de Ensino Superior (IES) no Brasil, avaliando as possíveis alterações ocorridas na formação inicial após 2002, em função das Diretrizes Curriculares Nacionais (DCN's). E como objetivos específicos almeja-se compreender os projetos de formação de professores de Geografia em consonância com a política nacional de formação docente implementada pelas DCN's; analisar a percepção dos alunos ingressos e egressos relativa aos aspectos de sua formação profissional; conhecer como se efetiva a prática, como componente curricular, nos cursos de formação de professores de Geografia; caracterizar a maneira pela qual a teoria e a prática se efetivam na formação do professor de Geografia; refletir sobre a descentralização e mudança da carga horária das disciplinas de domínio pedagógico ao longo da formação inicial do professor de Geografia, e analisar as concepções e as propostas de estágio presentes nos cursos de Licenciatura em Geografia.

Para atingir esses objetivos, optou-se pela metodologia do tipo estudo de caso, conforme a abordagem qualitativa de Lüdke e André (1986). Dentre suas características destacam-se: o uso de várias fontes de informação e a possibilidade de generalizações naturalísticas, quando o leitor associa os dados da pesquisa com a sua experiência, formulando assim conclusões próprias.

O caso desta pesquisa se configura no estudo dos impactos das DCN's nos cursos de Licenciatura em Geografia, tendo como base o projeto pedagógico e os sujeitos (docentes e discentes) envolvidos nessa formação após o ano de 2002. A delimitação do universo empírico da pesquisa se circunscreve inicialmente às Instituições de Ensino Superior (IES) no Brasil que têm o curso de Geografia, na qual trabalham os professores/pesquisadores membros do NEPEG.

Por se tratar de uma pesquisa coletiva, o desenvolvimento metodológico foi o mesmo para todas as instituições e cursos pesquisados. Nesse sentido, a realização da pesquisa conta com as seguintes etapas: Etapa 1 - Análise do projeto pedagógico dos 
cursos de Geografia, para conhecer a relação do projeto com as DCN's; a concepção do estágio e da prática como componente curricular; a relação teoria e prática; a posição e a carga horária das disciplinas pedagógicas. Etapa 2 - Análise da percepção dos docentes e discentes sobre os impactos das DCN's, para conhecer a percepção sobre a formação profissional; a prática como componente curricular; a relação teoria e prática e a descentralização das disciplinas pedagógicas. Etapa 3 - Análise da percepção dos docentes sobre o estágio e a formação pedagógica no contexto das DCN's, para entender a concepção dos docentes sobre a descentralização das disciplinas pedagógicas; a concepção e as propostas de estágio e de prática; bem como a contribuição dessa estrutura para a formação docente em Geografia. Etapa 4 - Análise das possíveis alterações nos cursos de Geografia no contexto das DCN's, feita por meio da análise dos dados coletados e tratados nas etapas anteriores amparada em referenciais teóricos sobre a formação docente e ainda nas discussões realizadas pelos pesquisadores no âmbito da pesquisa coletiva.

A elaboração e aplicação dos instrumentos de pesquisa e suas análises estão sendo desenvolvidas coletivamente no âmbito do NEPEG, tendo como subsídio o Grupo Gestor, formado por pesquisadores responsáveis pelo acompanhamento da pesquisa em todas as suas etapas.

Quadro 1: Instituições e cursos de Geografia participantes desta etapa da pesquisa, 2018.

\begin{tabular}{|c|c|c|}
\hline Região & Instituição/Localidade & Quantidade de cursos \\
\hline \multirow{3}{*}{$\begin{array}{l}\text { Centro- } \\
\text { Oeste }\end{array}$} & UFG (Goiânia e Jataí) & 02 \\
\hline & UEG (Anápolis, Goiás, Morrinhos, Porangatu, Minaçu) & 05 \\
\hline & UnB (Brasília) & 01 \\
\hline Norte & UFT (Porto Nacional e Araguaína) & 02 \\
\hline \multirow{4}{*}{ Nordeste } & UFPI (Teresina) & 01 \\
\hline & UFPB (João Pessoa) & 01 \\
\hline & UFCG (Cajazeiras e Campina Grande) & 02 \\
\hline & UEPB (Guarabira e Campina Grande) & 02 \\
\hline \multirow{3}{*}{ Sudeste } & UFU (Uberlândia) & 01 \\
\hline & UFMG (Belo Horizonte) & 01 \\
\hline & UFSJ (São João Del Rei) & 01 \\
\hline TOTAL & 11 & 19 \\
\hline
\end{tabular}

Fazem parte deste trabalho pesquisadores oriundos de 19 cursos de graduação em Geografia no Brasil, de 11 Instituições de Ensino Superior: Universidade Federal de Goiás (Goiânia e Jataí), Universidade Estadual de Goiás (Anápolis, Goiás, Morrinhos, 
Porangatu e Minaçu), Universidade de Brasília (Brasília), Universidade Federal do Tocantins (Porto Nacional e Araguaína), Universidade Federal do Piauí (Teresina), Universidade Federal da Paraíba (João Pessoa), Universidade Estadual da Paraíba (Guarabira, Campina Grande), Universidade Federal de Campina Grande (Cajazeiras e Campina Grande), Universidade Federal de Uberlândia (Uberlândia), Universidade Federal de Minas Gerais (Belo Horizonte) e Universidade Federal de São João Del Rei (São João Del Rei) (Quadro 01).

Por tratar-se de uma pesquisa em desenvolvimento, priorizar-se-á no presente trabalho a análise da primeira etapa, ou seja, a dos Projetos Pedagógicos Curriculares (PPC's) das instituições envolvidas na pesquisa, com destaque para os impactos já percebidos nesses projetos em função dessas DCN's. Aborda-se no próximo item as análises relativas a essa primeira etapa da pesquisa, a qual foi realizada tendo como subsídio um roteiro de análise pré-estruturado.

\section{Os projetos pedagógicos das instituições analisadas}

A primeira etapa da pesquisa circunscreveu-se à análise do projeto pedagógico dos cursos de Geografia para conhecer a relação do projeto com as DCN's; a concepção do estágio e da prática como componente curricular; a relação teoria e prática; a posição e a carga horária das disciplinas pedagógicas.

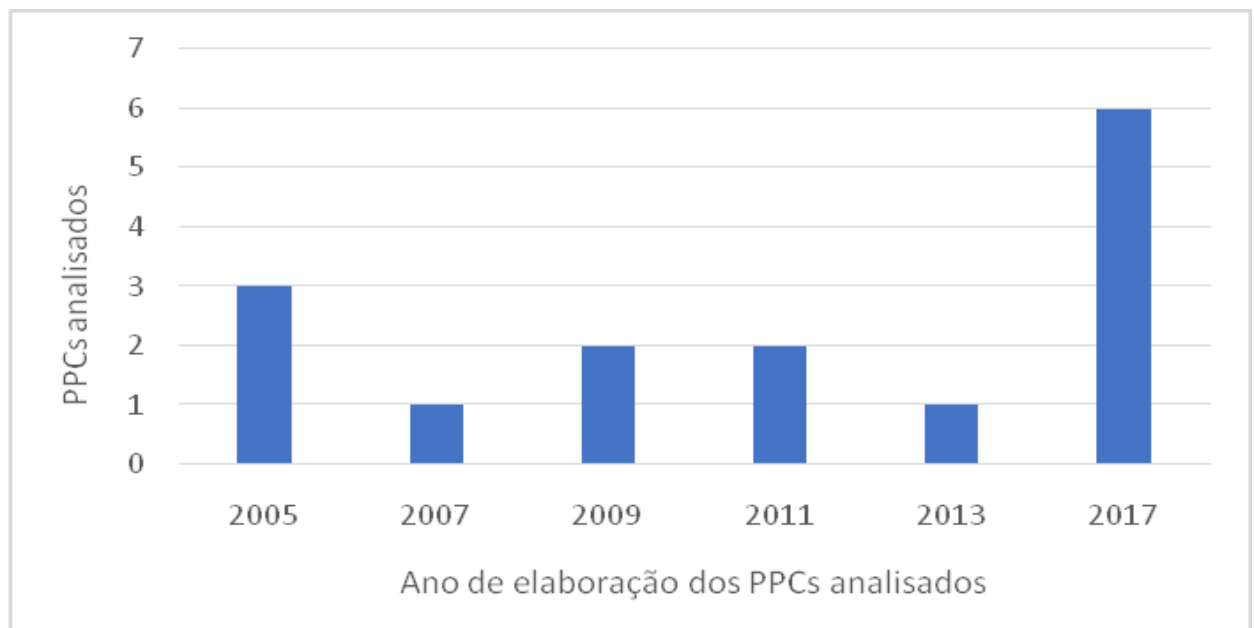

Figura 1: Ano de elaboração dos Projetos Pedagógicos Curriculares dos cursos de Geografia participantes desta etapa da pesquisa, 2018.

Fonte: PPC's analisados, 2018.

Nesse sentido, analisou-se o Projeto Pedagógico de 15 cursos de Geografia, os quais estão sediados em 11 Instituições de Ensino Superior no Brasil, situadas nas 
distintas regiões brasileiras, segundo a classificação do IBGE. Cumpre esclarecer que, o fato delas estarem situadas em diferentes regiões nos ajuda a entender como esses projetos tem sido pensado em alguns contextos do território nacional o que diverge de uma análise em termos estatísticos que considere a representatividade regional.

Quanto aos projetos pedagógicos dos cursos, foram analisados os PPC's de 15 cursos de Geografia, visto que na UEG é utilizado projeto pedagógico similar, com algumas adequações, nos diversos campus que a constituem. $\mathrm{O}$ primeiro foco de análise do PPC circunscreveu-se ao seu ano de elaboração, considerando as versões posteriores à aprovação das DCN's; ao(s) turno(s) em que é ofertado o curso de Geografia, bem como ao regime e à carga horária total do curso.

A par desses elementos, constatou-se que os projetos foram elaborados entre os anos de 2005 e 2017, sendo três em 2005, um em 2007, dois em 2009, dois em 2011, um em 2013 e seis em 2017 (Figura 1). Destaca-se, nesse conjunto, a produção tardia dos PPC's. Apenas três cursos o elaboraram até o ano de 2005, considerando que as DCN's foram aprovadas em 2002 e que havia a obrigatoriedade de aprová-los, inicialmente até o ano de 2004, o que posteriormente foi estendido até o ano de 2005, momento em que um novo currículo deveria ser "colocado em prática".

O art. 15 da Resolução CNE/CP 1/2002, estabelece que "Os cursos de formação de professores para a educação básica que se encontrarem em funcionamento deverão se adaptar a esta Resolução, no prazo de dois anos", portanto, considerando que a Resolução entrou em vigor em 4 de março de 2002, data de sua publicação no Diário Oficial da União, o prazo previsto no art. 15 esgotou-se em 4 de março de 2004. Todavia, a Comissão propôs que o mesmo fosse adiado até 15/10/2005, com o intuito de que ele vigorasse a partir de 2006 (Parecer CNE/CP 4/2004). Portanto, é considerando as DCN's de 2002 que as instituições de ensino têm elaborado os seus projetos pedagógicos.

Cumpre esclarecer que, após a aprovação das DCNs de 2002 várias resoluções e pareceres foram elaborados. Dentre eles merece destaque a Resolução CNE/CP $\mathbf{n}^{\mathbf{0}} 2$, de $1^{\circ}$ de julho de 2015, pois ao definir as Diretrizes Curriculares Nacionais para a formação inicial em nível superior (cursos de licenciatura, cursos de formação pedagógica para graduados e cursos de segunda licenciatura) e para a formação continuada, ela apresentou mudanças em relação ao que havia sido apresentado nas DCNs de 2002. Todavia, a Resolução No 1, de 9 de agosto de 2017 e a Resolução N ${ }^{\circ}$ 3, de 3 de outubro de 2018, estenderam o prazo para que as alterações propostas a partir dessa resolução entrassem em vigor. Conformee essa última resolução, o prazo findaria após um período de quatro anos, portanto, em 2019, conforme pode ser observado no art. 22 da Resolução $\mathrm{N}^{\mathrm{o}}$ 3, de 3 de outubro de 2018: "Art. 22. Os cursos de formação de professores, que se encontram em funcionamento, deverão se adaptar a esta Resolução no prazo improrrogável de 4 (quatro) anos, a contar da data de sua publicação.”, o que, consequentemente, faz com que essas alterações fujam ao escopo de análise do presente artigo. 
Quanto ao regime, essas instituições ofertam o curso de Geografia majoritariamente no formato semestral. Da totalidade das instituições, apenas a UEG oferece o curso no regime anual. No que tange ao turno em que o curso de licenciatura é ofertado, apenas uma instituição o disponibiliza somente no período diurno. As demais ofertam o curso à noite, sendo que apenas nove destas o ofertam também no diurno (Figura 2). Esse aspecto evidencia que uma parcela significativa desses estudantes é de trabalhadores, restando, portanto, o horário noturno para se dedicar aos estudos.

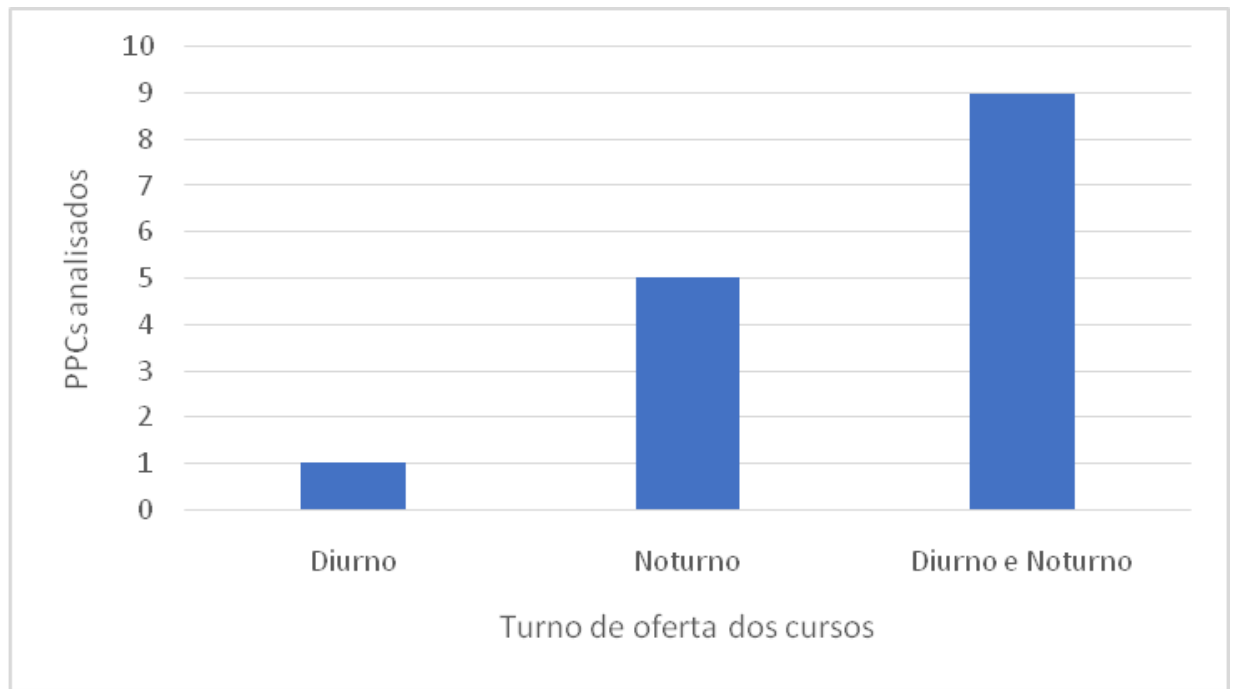

Figura 2: Turno de aulas dos cursos de Geografia participantes da pesquisa, 2018.

Fonte: PPC's analisados, 2018.

No que tange às cargas horárias das instituições analisadas, elas situam-se entre 2.850 e 3.560 horas. Oito instituições possuem carga horária entre 2.850 e 3.000 horas; seis, entre 3.001 e 3.500 horas, e uma com 3.560 horas (Figura 3). Portanto, elas atendem às questões apresentadas pela Resolução CNE/CP 2, de 19 de fevereiro de 2002, a qual estabelece em seu primeiro artigo que "A carga horária dos cursos de Formação de Professores da Educação Básica, em nível superior, em curso de licenciatura, de graduação plena, será efetivada mediante a integralização de, no mínimo, 2.800 (duas mil e oitocentas) horas". 


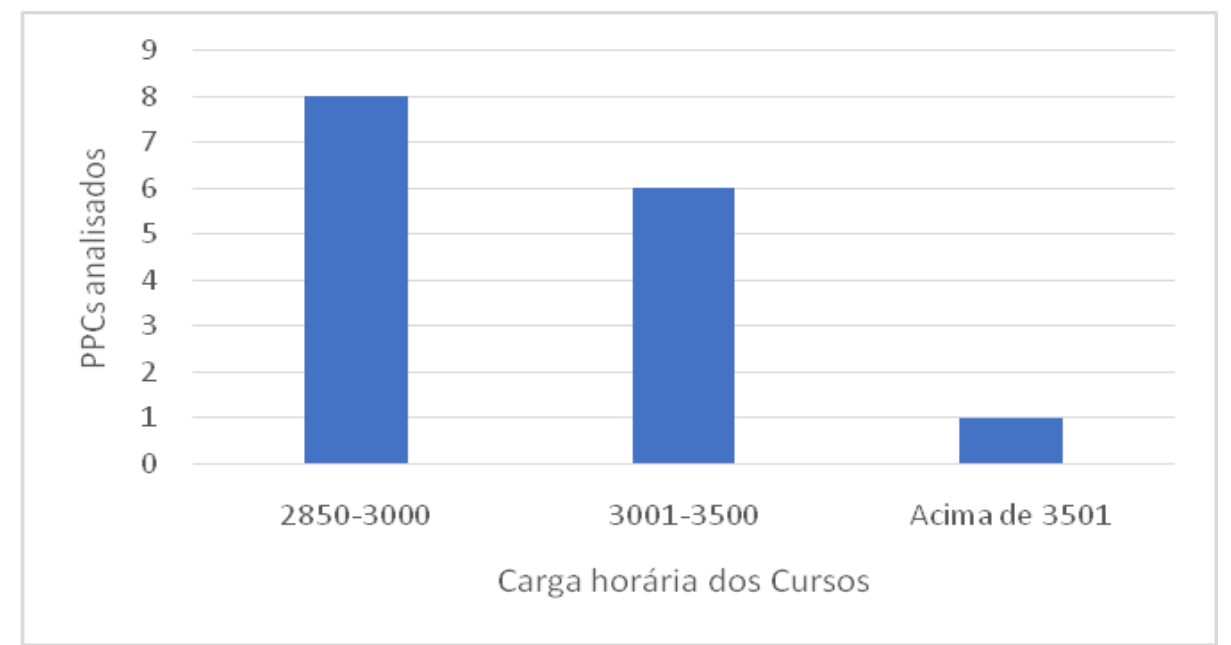

Figura 3: Carga horária dos cursos de Geografia participantes desta etapa da pesquisa, 2018. Fonte: PPC's analisados, 2018.

Acrescente-se que quase todas as instituições possuem em seu projeto itens como perfil dos formandos (exceto uma), competências e habilidades (exceto uma), estrutura do curso, formato dos estágios, conteúdos básicos e complementares, conteúdos definidos pela Educação Básica (exceto quatro), características das atividades complementares (exceto duas), e formas de avaliação (exceto duas), temas esses indicados como obrigatórios para serem apresentados nos PPC's das IES.

No que diz respeito às disciplinas de caráter pedagógico do curso, no parágrafo único do artigo 11 da Resolução CNE/CP 1, de 18 de fevereiro de 2002, explicita-se que

nas licenciaturas voltadas para a educação infantil e anos iniciais do ensino fundamental deverão preponderar os tempos dedicados à constituição de conhecimento sobre os objetos de ensino e, nas demais licenciaturas, o tempo dedicado às dimensões pedagógicas não será inferior à quinta parte da carga horária total.

Isso significa dizer que, em um curso com $2.800 \mathrm{~h}$, ao menos $560 \mathrm{~h}$ deverão ser destinadas às disciplinas pedagógicas. Ao analisar os PPC's das instituições participantes da pesquisa, constatamos que a carga horária de disciplinas pedagógicas é superior a esse montante quando integramos a essas disciplinas a carga horária relativa aos estágios. Quando vistas isoladamente, apenas uma instituição apresenta carga horária equivalente ao que é solicitado pela legislação (Figura 4). 


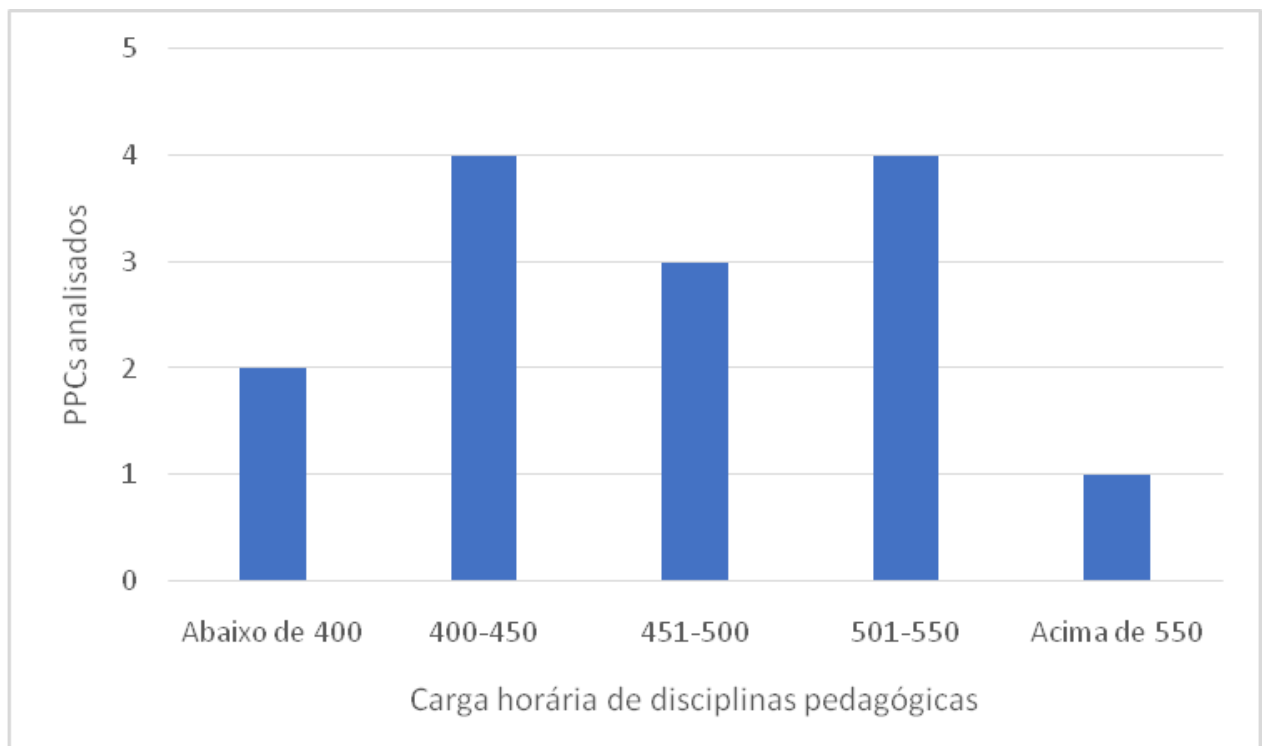

Figura 4 - Carga horária das disciplinas pedagógicas dos Projetos Pedagógicos Curriculares dos cursos de Geografia participantes desta etapa da pesquisa, 2018.

Fonte: PPC's analisados, 2018.

Outro item analisado circunscreveu-se à prática como componente curricular. $\mathrm{O}$ parecer CNE/CES No 15/2005 explicita que “(...) a prática como componente curricular é o conjunto de atividades formativas que proporcionam experiências de aplicação de conhecimentos ou de desenvolvimento de procedimentos próprios ao exercício da docência". Isso significa dizer que se trata de uma dimensão do conhecimento que está presente nos cursos de formação tanto nos momentos em que se trabalha com o estágio quanto nos momentos em que o foco é a reflexão sobre a atividade profissional, devendo permear toda a formação do futuro professor (PARECER CNE/CP 9/2001). Essa mesma direção é apontada pela RESOLUÇÃO CNE/CP 1, de 18 de fevereiro de 2002, ao expressar que a dimensão prática deverá ser trabalhada por todas as disciplinas e não apenas pelas disciplinas pedagógicas.

No que circunscreve à concepção da Prática como Componente Curricular, seis instituições expressam essa concepção nos projetos pedagógicos e, destas, apenas duas apresentam a distribuição dessa carga horária nas disciplinas. Portanto, ao verificarmos que o CNE estabelece que 400 horas dos cursos de formação de professores fossem destinadas a esse componente curricular, vivenciadas ao longo do curso, destacamos de um lado a obrigatoriedade estabelecida pela legislação e, de outro, o ganho que essa formação passa a ter, visto que a profissionalidade docente passa a situar-se no centro da formação dos futuros professores. Isso permite, por exemplo, a integração entre conhecimentos geográfico, pedagógico e didático, associados à realidade do ambiente 
escolar. Essas questões podem ser mais bem compreendidas com a leitura do fragmento a seguir:

\begin{abstract}
A prática não é uma cópia da teoria e nem esta é um reflexo daquela. A prática é o próprio modo como as coisas vão sendo feitas, cujo conteúdo é atravessado por uma teoria. Assim, a realidade é um movimento constituído pela prática e pela teoria como momentos de um devir mais amplo, consistindo a prática no momento pelo qual se busca fazer algo, produzir alguma coisa, e que a teoria procura conceituar, significar e, com isso, administrar o campo e o sentido desta atuação. (RESOLUÇÃO CNE/CP 1, DE 18 DE FEVEREIRO DE 2002).
\end{abstract}

No que se refere ao estágio, verificou-se que ele possui carga horária entre 400 e 645 horas, predominando aquelas situadas entre 400 e 450 horas (Figura 5). Assim, a normatização do CNE/2002 tem sido utilizada como subsídio, uma vez que esse conselho aponta a necessidade de perfazer, no mínimo, 400 (quatrocentas) horas de estágio curricular supervisionado a partir do início da segunda metade do curso.

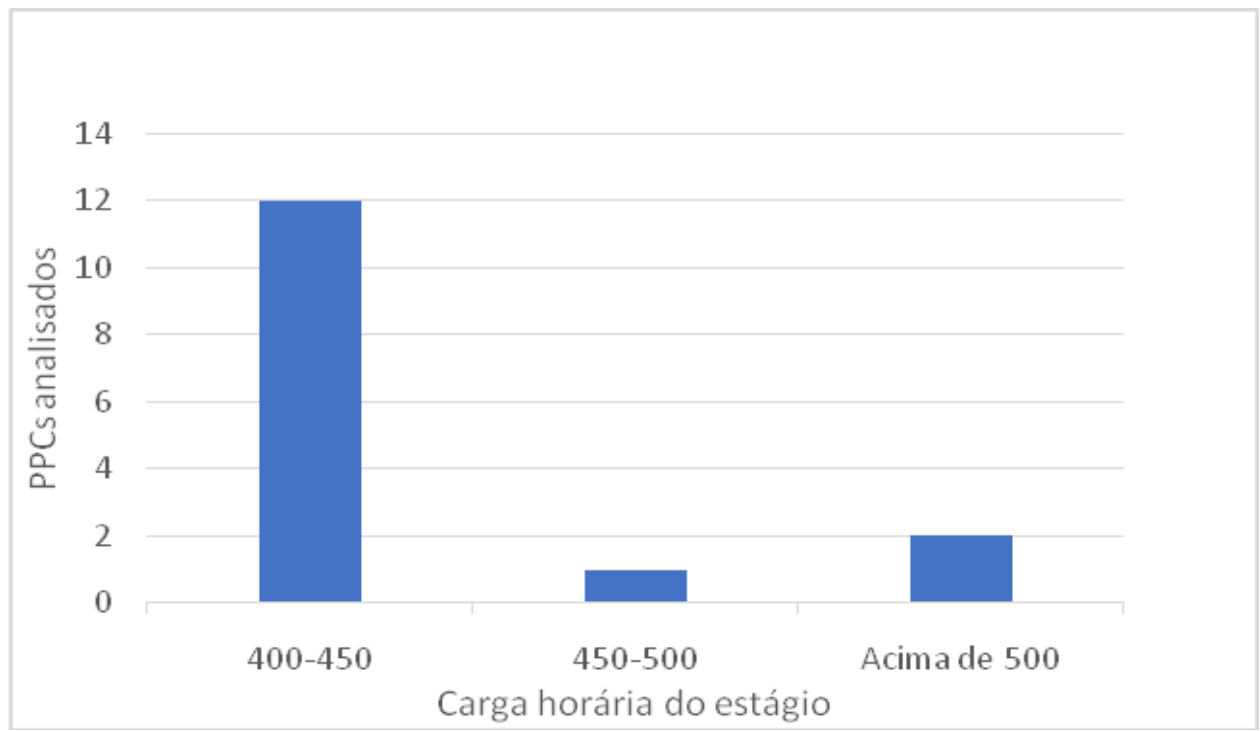

Figura 5 - Carga horária do estágio nos Projetos Pedagógicos Curriculares os cursos de Geografia participantes desta etapa da pesquisa, 2018.

Fonte: PPC's analisados, 2018.

A alteração realizada quanto ao formato de desenvolvimento do estágio nos cursos de formação de professores, comparativamente ao período anterior à aprovação das DCN's, tem o propósito de qualificar a formação, visto que nesse formato e com essa carga horária cria-se a possibilidade de uma aproximação maior com o ambiente de 
trabalho dos futuros professores, auxiliando-os a problematizar questões específicas de sua atuação profissional durante a sua formação.

Os estágios têm sido desenvolvidos ao longo do curso, sob o acompanhamento de docentes do ensino superior e docentes da Educação Básica, sendo estruturados em duas, três ou quatro disciplinas, das quais predomina o montante de quatro disciplinas, bem como a terminologia Estágio Supervisionado em Geografia (I, II, III, IV).

Ao analisar a relação teoria e prática nos cursos de formação de professores investigados, verificamos que 11 dos 15 cursos apresentam essa relação em seus projetos pedagógicos, numa perspectiva de construir o conhecimento associando teoria e prática. Esse aspecto evidencia o destaque que tem sido dado a essa temática nos projetos pedagógicos, o que, embora não seja uma garantia, sinaliza que a práxis tem a possibilidade de ser efetivada nesses cursos de formação. Esse tema tem sido destacado como uma referência importante para os cursos de formação de professores (GARCIA, 2013).

Quanto à pesquisa na formação docente, constatou-se que, dos projetos analisados, nove apresentam essa proposição. Ter a pesquisa como fio condutor dos cursos de formação de professores auxilia os alunos na construção do conhecimento durante e após a sua formação, visto que, ao atuarem na educação básica, podem utilizar essa perspectiva para encaminhar o processo de ensino e aprendizagem. Encaminhar o ensino nessa perspectiva permite problematizar e intervir na realidade, avaliando a atuação dos sujeitos envolvidos na construção do espaço geográfico.

A partir da análise dos projetos pedagógicos das instituições participantes da pesquisa constatamos que, embora vários projetos tenham sido elaborados tardiamente, eles têm tentado se adequar ao que é preconizado pela legislação, no que circunscreve à sua elaboração. Se por um lado isso não necessariamente indica que a formação dos professores esteja sendo realizada totalmente sob esses preceitos, por outro lado, ao ser sistematizado ele tanto apresenta possibilidades de encaminhá-lo nesse formato quanto se torna um marco legal que auxilia alunos, professores e gestores no alcance de muitas conquistas que ele representa para a formação de professores.

Dentre essas conquistas destacamos o fato de a prática ser concebida como uma componente curricular, que está situada na perspectiva de contribuir para a profissionalidade docente; e o estágio, ao ser realizado ao longo da formação, mais especificamente a partir da segunda metade do curso, possibilita a aproximação entre a universidade e a escola básica.

\section{Considerações finais}

Ao longo desta pesquisa, constatamos que a articulação relacionando o conteúdo à metodologia de ensino não é apresentada na maioria dos projetos pedagógicos dos cursos investigados. Ter essa articulação como referência é importante 
para a autonomia dos professores, para que eles saibam como são produzidos os conhecimentos que ministram, no que se refere aos métodos de investigação.

Acreditamos que os resultados parciais desta pesquisa, embora sejam relativos a algumas das instituições brasileiras que ofertam o curso de Licenciatura em Geografia, refletem aquilo que comumente está posto nos PPC's para a formação de professores de Geografia em nível nacional.

No que se refere à elaboração tardia dos PPC's, apenas três cursos o elaboraram até o ano de 2005. Considerando que as DCN's foram aprovadas em 2002, observamos um descompasso temporal entre as orientações curriculares lançadas e, consequentemente, a efetivação dessas na prática profissional, no intervalo de tempo que corresponde a sua dada realidade.

Quanto à concepção da Prática como Componente Curricular, verificamos um descompasso quanto à exigência do CNE, que estabelece 400 horas dos cursos de formação de professores, pois apenas seis instituições expressam essa concepção nos projetos pedagógicos. Podemos inferir que a cultura universitária de formação de professores ainda continua arraigada nos modelos dicotômicos de teoria e prática, e não na sua relação de interdependência.

Relativo à carga horária de estágio curricular supervisionado entre 400 e 645 horas, a grande maioria dos cursos atende a normatização exigida pelo $\mathrm{CNE} / 2002$. O atendimento dessa exigência amplia as possibilidades de o professor em formação vivenciar cenários de planejamento, operacionalização e reflexão da realidade escolar, bem como confrontá-los teoricamente.

A análise desses dados circunscreveu-se apenas à primeira etapa da pesquisa, a qual situou-se na análise documental. Com o intuito de compreender a Geografia Escolar no contexto dos cursos analisados, prevê-se a realização das etapas dois, três e quatro, as quais, conforme apresentado anteriormente, culminam com a compreensão das possíveis alterações ocorridas nos cursos de Geografia no contexto das DCN's.

\section{Referências}

BRASIL. Parecer CNE/CP 009/2001, de 8 de maio de 2001. Diretrizes Curriculares Nacionais para a Formação de Professores da Educação Básica, em nível superior, curso de licenciatura, de graduação plena. Publicado no Diário Oficial da União, Brasília, DF, 18 de jan. 2002. seção 1. p.31. Disponível em: http://portal.mec.gov.br/cne/arquivos/pdf/009.pdf. Acesso em: 10/06/2017.

BRASIL. Parecer CNE/CP 28/2001, de 2 de outubro de 2001. Dá nova redação ao Parecer CNE/CP 21/2001, que estabelece a duração e a carga horária dos cursos de Formação de Professores da Educação Básica, em nível superior, curso de licenciatura, de graduação plena. Publicado no Diário Oficial da União de 18/1/2002, Seção 1, p.31. 
BRASIL. Resolução CNE/CP 01, de 18 de fevereiro de 2002.. Disponível em: http://portal.mec.gov.br/cne/arquivos/pdf/rcp01_02.pdf . Acesso em: 10/06/2017.

BRASIL. Resolução CNE/CP 2, de 19 de fevereiro de 2002. Diário Oficial da União, Brasília, DF, 4 de mar de 2002, seção 1, p.9. Institui a duração e a carga horária dos cursos de licenciatura, de graduação plena, de formação de professores da Educação Básica em nível superior. Disponível em: <http://portal.mec.gov.br/cne/arquivos/pdf/CP022002.pdf.> Acesso em: 01/06/2017.

BRASIL. Parecer CNE/CP 4/2004. Adiamento do prazo previsto no art. 15 da Resolução CNE/CP 1/2002, que institui Diretrizes Curriculares Nacionais para a Formação de Professores da Educação Básica, em nível superior, curso de licenciatura, de graduação plena. Disponível em http://portal.mec.gov.br/cne/arquivos/pdf/p04.pdf. Acesso em 10/06/2017.

BRASIL. Resolução CNE/CP 1, 17 de novembro de 2005. Altera a Resolução CNE/CP $n^{\circ}$ 1/2002, que institui as Diretrizes Curriculares Nacionais para a Formação de Professores da Educação Básica, em nível superior, curso de Licenciatura de graduação plena. Disponível em http://portal.mec.gov.br/. Acesso em: 10/06/2017.

BRASIL. 2017. RESOLUÇÃO $N^{\circ} 1$, DE 9 DE AGOSTO DE 2017. Altera o Art. 22 da Resolução CNE/CP n ${ }^{\circ}$ 2, de $1^{\circ}$ de 2015 , que define as Diretrizes Curriculares Nacionais para a formação inicial em nível superior (cursos de licenciatura, cursos de formação pedagógica para graduados e cursos de segunda licenciatura) e para a formação continuada. Disponível em http://portal.mec.gov.br/index.php?option=com_docman\&view=download\&alias=70141 -rcp001-17-pdf\&category_slug=agosto-2017-pdf\&Itemid=30192. Acesso em: 201/10/2018.

BRASIL. 2018. RESOLUÇÃO $N^{o} 3$, de 3 de outubro de 2018. Altera o Art. 22 da Resolução CNE/CP n ${ }^{\circ}$ 2, de $1^{\circ}$ de 2015, que define as Diretrizes Curriculares Nacionais para a formação inicial em nível superior (cursos de licenciatura, cursos de formação pedagógica para graduados e cursos de segunda licenciatura) e para a formação continuada. Disponível em http://portal.mec.gov.br/docman/outubro-2018-pdf-1/98131rcp003-18/file. Acesso em: 20/10/2018.

GARCIA, M. M. A; FONSECA, M. S. da; LEITE, V. C. Teoria e prática na formação de professores: a prática como tecnologia do eu docente. Educação em Revista, v.29, n.03, p.233-264, 2013.

LUDKE, M.; ANDRÉ, M. Pesquisa em educação: abordagens qualitativas. São Paulo: EPU, 1986.

MORAIS, E. M. B. de; OLIVEIRA, K. A. T. de. Estágio Supervisionado e práticas curriculares: uma leitura dos cursos de formação de professores de Geografia das Universidades Católica, Estadual e Federal de Goiás. In: CAVALCANTI, L. de S. (Org.). Temas Geográficos. Goiânia: Editora da UFG: CEGRAF, 2008, p. 169-188. 
PIMENTA, S. G.; LIMA, M. S. L. Estágio e Docência. São Paulo: Cortez, 2004.

SANTOS, Milton. O espaço do cidadão. 5ed. São Paulo: Nobel, 1998. p.126.

\author{
Eliana Marta Barbosa de Morais \\ Doutora em Geografia pela Universidade de São Paulo, com estágio sanduíche na \\ Universidade Autônoma de Madrid - (Espanha). Mestre e graduada em Geografia \\ pela Universidade Federal de Goiás. Atualmente é professora efetiva da Universidade \\ Federal de Goiás, na graduação e na pós-graduação. \\ Avenida Esperança, s/n - Samambaia, Goiânia-GO, Cep.74001-970. \\ E-mail: elianamarta.ufg@gmail.com
}

\title{
Adriana Olívia Alves
}

Doutora, mestre, bacharel e licenciada em Geografia pela Universidade Estadual Paulista (UNESP), Campus de Presidente Prudente-SP, com estágio sanduíche na Université de Loulouse - Le Mirail (França). Atualmente é professora efetiva da Universidade Federal de Goiás, na graduação e na pós-graduação.

Avenida Esperança, s/n - Samambaia, Goiânia-GO, Cep.74001-970.

E-mail: adrianaolivia.ufg@gmail.com

\section{Míriam Aparecida Bueno}

Doutora em Geografia pela Universidade Estadual de Campinas, mestre em Geografia pela Universidade Federal de Minar Gerais, com pós-doc na área de Ensino de Geografia pela Universidade Federal da Paraíba. Atualmente é professora efetiva da Universidade Federal de Goiás, na graduação e na pós-graduação.

Avenida Esperança, s/n - Samambaia, Goiânia-GO, Cep.74001-970.

E-mail: miriam.cerrado@gmail.com

Recebido para publicação em maio de 2018 Aprovado para publicação em agosto de 2018 